\title{
Pharmacokinetics and Pharmacodynamics of Nifedipine in Children with Bronchopulmonary Dysplasia and Pulmonary Hypertension
}

\author{
CARY E. JOHNSON, ROBERT H. BEEKMAN, DARIA A. KOSTYSHAK, TRACI NGUYEN, \\ DOO-MAN OH, AND GORDON L. AMIDON \\ College of Pharmacy and Division of Pediatric Cardiology, C. S. Mott Children's Hospital, University of \\ Michigan, Ann Arbor, Michigan 48109
}

\begin{abstract}
The pharmacokinetics and associated pharmacodynamics of nifedipine were studied in nine children aged 5 to $68 \mathrm{mo}$ with bronchopulmonary dysplasia and pulmonary artery hypertension after a single oral dose of $1.44 \mu \mathrm{mol} / \mathrm{kg}(0.5 \mathrm{mg} / \mathrm{kg})$. In the cardiac catheterization laboratory, hemodynamic measurements were made in duplicate just before the nifedipine dose and at $5 \mathrm{~min}$ and 0.5 and $1.0 \mathrm{~h}$ after the dose. The plasma nifedipine concentration was measured by HPLC at each of the above times and at $2.5,4.0,6.0$, and $8.0 \mathrm{~h}$ after the dose. The mean $( \pm$ SD) maximum plasma concentration and the time to maximum plasma concentration were $243.4 \pm 194.5 \mathrm{nmol} / \mathrm{L}$ and $1.0 \pm 0.8 \mathrm{~h}$, respectively. The mean area under the plasma concentration-time curve was $761 \pm 509 \mathrm{nmol} \cdot \mathrm{h} /$ L. The mean elimination rate constant and $t_{1 / 2}$ were 0.456 $\pm 0.194 \mathrm{~h}^{-1}$ and $1.8 \pm 0.8 \mathrm{~h}$, respectively. Nifedipine caused a significant $(p \leq 0.05)$ reduction in the mean pulmonary artery pressure by $5 \mathrm{~min}$ and in the mean pulmonary vascular resistance index and mean aortic pressure by 30 min, and these reductions remained significant through the 1-h measurement interval. The magnitude of acute hemodynamic response correlated closely with the plasma nifedipine concentrations. No significant change occurred in the mean arterial oxygen saturation or cardiac index during the study period. The percentage changes from baseline in the mean pulmonary artery pressure and mean pulmonary vascular resistance index were approximately double the percentage change in the mean aortic pressure, suggesting that nifedipine had some degree of selective impact on the pulmonary vascular bed. Based on these results, an initial oral maintenance regimen of $1.44 \mu \mathrm{mol} / \mathrm{kg}(0.5 \mathrm{mg} / \mathrm{kg})$ every $6 \mathrm{~h}$ would be needed for this patient population. If the safety and efficacy after chronic therapy can also be shown, nifedipine may prove to be an important therapeutic addition to the management of children with bronchopulmonary dysplasia and pulmonary hypertension. (Pediatr Res 29: 500-503, 1991)
\end{abstract}

\section{Abbreviations}

BPD, bronchopulmonary dysplasia

Cmax, maximum plasma concentration

Tmax, time to Cmax

mPAP, mean pulmonary artery pressure

AOP, mean aortic pressure

PR, pulmonary vascular resistance index

Received October 3, 1990; accepted January 7, 1991

Correspondence and reprint requests: Cary E. Johnson, Pharm.D., University of Michigan College of Pharmacy, 428 Church Street, Ann Arbor, MI 48109.1065. Supported in part by NIH General Clinical Research Center Grant 5M01RR00042 and NIGMS Grant GM 37188. $\mathrm{k}$, elimination rate constant

AUC, area under the concentration-time curve

Premature infants who develop respiratory distress syndrome require assisted positive pressure ventilation with high concentrations of supplemental oxygen. Therapy with oxygen at high atmospheric pressure to an already compromised lung may cause prolongation of the normal healing phase of respiratory distress syndrome and may be a factor in the development of BPD (1). $\mathrm{BPD}$, in turn, may cause pulmonary hypertension, primarily by hypoxia-induced constriction of pulmonary vascular smooth muscle. Long-term complications of severe BPD include abnormal pulmonary function with exercise limitations, failure to thrive, and cor pulmonale (2).

Therapy for infants with BPD has been primarily supportive and has included minimizing all respiratory tract insults, compensating for complications of hypoxia, and maintaining nutritional support during recovery. Pharmacologic management has been limited, but may include diuretics and, at times, cardiac glycosides. Treatment of pulmonary artery hypertension has been impeded by the lack of a selective pulmonary vasodilating agent other than oxygen. Several studies have demonstrated that hypoxia-induced pulmonary vasoconstriction may be related to transmembrane extracellular calcium influx; therefore, nifedipine, a calcium channel blocking agent, has been evaluated as a potential therapeutic option in children with BPD and pulmonary hypertension (3-5).

Although the pharmacokinetics and pharmacodynamics of nifedipine have been characterized extensively in adults (6-9), only a few studies to date have evaluated the hemodynamic responses in a pediatric population (3-5), and pharmacokinetic studies in this population are completely lacking. The objectives of this study were to determine the pharmacokinetic properties of nifedipine in children with BPD and pulmonary artery hypertension after the administration of a single oral dose of the drug, and to evaluate the relationship between plasma nifedipine concentrations and the acute responses.

\section{MATERIALS AND METHODS}

Patients. Nine children, aged 5 to $68 \mathrm{mo}$, met the entry criteria and were enrolled in the study. The study protocol was approved by the Human Use Committee at The University of Michigan Medical center, and informed consent for participation in the study was obtained from each patient's parent or legal guardian. Criteria for entrance into this study were: 1 ) the presence of $\mathrm{BPD}$, documented by a history of positive pressure ventilation as a newborn, supplemental oxygen dependency to maintain 
arterial oxygen saturation greater than $80 \%$, the clinical presence of rales, rhonchi, and/or tachypnea, and characteristic radiographic findings on chest $\mathrm{X}$-ray (10);2) the presence of pulmonary artery hypertension [resting mPAP exceeding $2.7 \mathrm{kPa}(20 \mathrm{~mm}$ $\mathrm{Hg}$ ); and 3 ) the absence of structural heart disease. Before entry into this study, the clinical management of each child was guided by the referring pediatrician.

Study design. At the time of the study, each child was maintained on his usual medical regimen; however, the children received nothing by mouth, including medications, after midnight of the night before cardiac catheterization. Each patient was lightly sedated with oral chloral hydrate, and a complete right and left heart catheterization was performed to document the presence of pulmonary hypertension and the absence of structural heart disease. Each patient received a nifedipine dose of $1.44 \mu \mathrm{mol} / \mathrm{kg}(0.5 \mathrm{mg} / \mathrm{kg})$, which was based on the results of a previous study in which patients who had received greater than $1.73 \mu \mathrm{mol} / \mathrm{kg}(0.6 \mathrm{mg} / \mathrm{kg})$ had a decrease in aortic mean pressure exceeding $20 \%$ (4). The volume of liquid to provide the calculated dosage was withdrawn from a $10-\mathrm{mg}$ nifedipine capsule using a tuberculin syringe after a standardized procedure (11). The needle was removed from the syringe, and the nifedipine liquid was administered into the proximal oral cavity of each child. Due to limitations on the amount of blood that could be obtained from this patient population, venous blood samples were obtained for measurement of plasma nifedipine concentration predose and at $5 \mathrm{~min}$ and $0.5,1.0,2.5,4.0,6.0$, and $8.0 \mathrm{~h}$ after nifedipine administration. Each sample was immediately wrapped in aluminum foil to protect it from potential photodeg. radation (12), and the plasma was separated and frozen at $-20^{\circ} \mathrm{C}$ until analysis.

Hemodynamic measurements were made in duplicate just before the nifedipine dose and at $5 \mathrm{~min}$ and 0.5 and $1.0 \mathrm{~h}$ after the dose with the patient breathing room air or the lowest amount of supplemental oxygen tolerated (patients 2 and 9 were receiving $4 \mathrm{~L} / \mathrm{min}$ and $2 \mathrm{~L} / \mathrm{min}$ by nasal cannula, respectively, and patient 7 was on a ventilator at $80 \%$ fraction of inspired oxygen). The hemodynamic data collected included: pressures in the aorta, pulmonary artery, pulmonary capillary wedge position, and right atrium; thermodilution cardiac output (in triplicate); heart rate; arterial oxygen saturation, and arterial blood gas. Pulmonary and systemic vascular resistance were calculated as the mean pressure gradient between the arterial and venous bed divided by the indexed cardiac output. After the hemodynamic study, each patient was carefully observed overnight.

Nifedipine measurements. Nifedipine plasma concentrations were determined by HPLC according to the method described by Pietta et al. (12). This assay had a sensitivity of $28.9 \mathrm{nmol} / \mathrm{L}$ $(10 \mathrm{ng} / \mathrm{mL}$ ) and was specific for nifedipine with a coefficient of variation of less than $5 \%$ over the range of nifedipine concentrations encountered in the study.

Data analysis. Nifedipine plasma concentration-time data were analyzed by standard noncompartmental methods to derive pharmacokinetic values. The Cmax, the Tmax, and the AUC were obtained directly from the concentration-time data. The AUC was calculated using the trapezoidal method. The AUC was extrapolated to infinity by adding the area after the last measurable nifedipine plasma concentration, estimated by dividing the last measurable nifedipine plasma concentration by the terminal $\mathrm{k}$. Individual estimates of $\mathrm{k}$ were computed for a loglinear regression of nifedipine plasma concentration versus time for points in the elimination phase of drug distribution. Half-life was determined as $\ln 2 / \mathrm{k}$.

Hemodynamic values for mPAP, PR, cardiac index, and mean AOP were expressed as the mean $\pm \mathrm{SD}$. Statistical differences in each of these parameters at each measurement time after administration of nifedipine as compared to pretreatment values (time zero, before administration of nifedipine) were determined by single-factor, repeated measures analysis of variance. Where differences were noted, Duncan's multiple range test was used to evaluate at which measurement times statistical differences ( $p=$ $0.05)$ existed.

\section{RESULTS}

Pharmacokinetics. The nine study patients ranged in age from 5 to $68 \mathrm{mo}$ and in weight from 6.37 to $20.70 \mathrm{~kg}$ (Table 1). All but one child was receiving chronic diuretic therapy. The mean $( \pm$ SEM) plasma nifedipine concentrations as a function of time after a single oral dose of $1.44 \mu \mathrm{mol} / \mathrm{kg}(0.5 \mathrm{mg} / \mathrm{kg})$ are shown in Figure 1. Selected pharmacokinetic values for nifedipine are presented in Table 2 .

Pharmacodynamics. The time course of the hemodynamic responses to nifedipine is presented in Table 3. Nifedipine caused a significant reduction in the $\mathrm{mPAP}$ at $5 \mathrm{~min}$ and the PR and $A O P$ at $30 \mathrm{~min}$, and these reductions remained significant through the 1-h measurement interval. No significant change occurred in the mean arterial oxygen saturation or cardiac index during the study period (Table 3 ). The heart rate and mixed venous oxygen saturation also remained unchanged. The mean $( \pm \mathrm{SD})$ pretreatment arterial $\mathrm{pH}$ and $\mathrm{PCO}_{2}$ measurements for the study patients were $7.36 \pm 0.05$ and $6.88 \pm 2.37 \mathrm{kPa}(51.7 \pm$

Table 1. Demographic data for study patients

\begin{tabular}{|c|c|c|c|c|}
\hline Patient & $\begin{array}{l}\text { Age } \\
(\mathrm{mo})\end{array}$ & Sex & $\begin{array}{l}\text { Weight } \\
(\mathrm{kg})\end{array}$ & Medications \\
\hline 1 & 8 & M & 6.37 & $\begin{array}{l}\text { Chlorothiazide, furo- } \\
\text { semide, spirono- } \\
\text { lactone }\end{array}$ \\
\hline 2 & 8 & M & 6.86 & $\begin{array}{l}\text { Digoxin, furosemide, } \\
\text { spironolactone }\end{array}$ \\
\hline 3 & 28 & $\mathrm{~F}$ & 9.52 & $\begin{array}{l}\text { Digoxin, furosemide, } \\
\text { spironolactone }\end{array}$ \\
\hline 4 & 39 & $F$ & 10.01 & $\begin{array}{l}\text { Furosemide, spiro- } \\
\text { nolactone }\end{array}$ \\
\hline 5 & 20 & M & 7.75 & $\begin{array}{l}\text { Chlorothiazide, spi- } \\
\text { ronolactone }\end{array}$ \\
\hline 6 & 12 & $\mathrm{~F}$ & 6.80 & $\begin{array}{l}\text { Chlorothiazide, furo- } \\
\text { semide, spirono- } \\
\text { lactone }\end{array}$ \\
\hline 7 & 5 & $\mathrm{~F}$ & 2.38 & None \\
\hline 8 & 8 & $\mathrm{~F}$ & 6.00 & Furosemide \\
\hline 9 & 68 & M & 20.70 & $\begin{array}{l}\text { Chlorothiazide, spi- } \\
\text { ronolactone }\end{array}$ \\
\hline
\end{tabular}

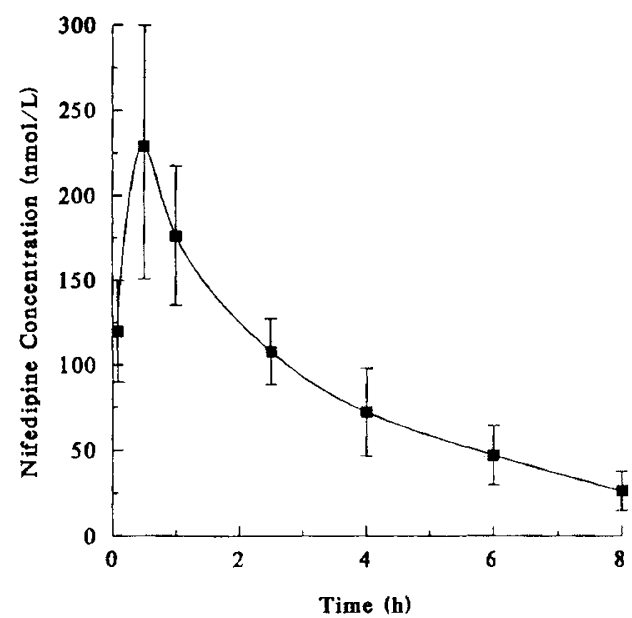

Fig. 1. Mean $( \pm$ SEM $)$ nifedipine plasma concentrations after a single dose of $1.44 \mu \mathrm{mol} / \mathrm{kg}(0.5 \mathrm{mg} / \mathrm{kg})$. The number of subjects included in the calculation of each data point was as follows: $5 \mathrm{~min}, 0.5,1.0$, and $2.5 \mathrm{~h}, n=9 ; 4.0$ and $6.0 \mathrm{~h}, n=6 ; 8.0 \mathrm{~h}, n=3$. The remaining subjects at the 4-, 6-, and 8-h time intervals had undetectable plasma nifedipine concentrations. 
Table 2. Pharmacokinetic parameters for nifedipine

\begin{tabular}{lccccc}
\hline Patient & $\begin{array}{c}\text { Cmax } \\
(\mathrm{nmol} / \mathrm{L})^{*}\end{array}$ & $\begin{array}{c}\text { Tmax } \\
(\mathrm{h})\end{array}$ & $\begin{array}{c}\text { AUC } \\
(\mathrm{nmol} \cdot \mathrm{h} / \mathrm{L})^{*} \dagger\end{array}$ & $\begin{array}{c}\mathrm{k} \\
\left(\mathrm{h}^{-1}\right)\end{array}$ & $\begin{array}{c}\mathrm{t}_{1 / 2} \\
(\mathrm{~h})\end{array}$ \\
\hline 1 & 77.7 & 0.4 & 217 & 0.432 & 1.6 \\
2 & 354.6 & 0.9 & 1965 & 0.218 & 3.2 \\
3 & 119.4 & 0.4 & 480 & 0.282 & 2.4 \\
4 & 124.0 & 2.7 & 916 & 0.273 & 2.5 \\
5 & 687.0 & 0.4 & 971 & 0.815 & 0.8 \\
6 & 340.4 & 0.3 & 725 & 0.558 & 1.2 \\
7 & 224.8 & 0.4 & 460 & 0.646 & 1.1 \\
8 & 160.1 & 1.4 & 601 & 0.480 & 1.4 \\
9 & 102.9 & 1.7 & 514 & 0.404 & 1.7 \\
Mean & 243.4 & 1.0 & 761 & 0.456 & 1.8 \\
SD & 194.5 & 0.8 & 509 & 0.194 & 0.8 \\
\hline
\end{tabular}

* $2.89 \mathrm{nmol} / \mathrm{L}=1 \mathrm{ng} / \mathrm{mL}$.

$\dagger$ Calculated from time zero to time infinity.

$17.8 \mathrm{~mm} \mathrm{Hg}$ ), respectively, and these values did not significantly change after nifedipine administration.

Figure 2 shows the correlations between mean plasma nifedipine concentrations and the percentage changes compared to baseline (time zero, before administration of nifedipine) in mPAP, PR, and AOP, respectively, as a function of time. Extrapolating the PR and AOP values to baseline, there is little or no hysteresis in the plots, suggesting that plasma nifedipine concentrations correlate closely with the magnitude of acute hemodynamic response. Extrapolation of the mPAP values to baseline also shows very little hysteresis in the plot but must be interpreted more cautiously because the mPAP response to nifedipine has not begun to fall at the $1-h$ measurement time.

\section{DISCUSSION}

There have been no previous studies describing the pharmacokinetic and pharmacodynamic properties of nifedipine in pediatric patients. Although evaluation of these properties in a group of patients with BPD and pulmonary hypertension may contribute to the significant interpatient variability observed, the results in general have been comparable to other studies in normal adults. The mean $\mathrm{Cmax}$ of $243.3 \mathrm{nmol} / \mathrm{L}$ observed in this study after a dose of $1.44 \mu \mathrm{mol} / \mathrm{kg}(0.5 \mathrm{mg} / \mathrm{kg})$ was similar to the mean value of $212.4 \mathrm{nmol} / \mathrm{L}$ reported by Foster et al. (13) in 12 normal adults and $280.3 \mathrm{nmol} / \mathrm{L}$ reported by Feher et al. (8) in 10 normal adults after a single oral dose of a $10-\mathrm{mg}$ nifedipine capsule. A value of $387.5 \mathrm{nmol} / \mathrm{L}$ was reported by Palma-Aguirre et al. (14) in six healthy male subjects. Although the plasma concentrations for this pediatric population were comparable to values observed in normal adults, the $\mu \mathrm{mol} / \mathrm{kg}$ oral dose of nifedipine was higher $(1.44 \mu \mathrm{mol} / \mathrm{kg}$ as compared to approximately $0.41 \mu \mathrm{mol} / \mathrm{kg}$ ). This difference may be due to several factors, including a reduced bioavailability (decreased extent of absorption or increased first-pass metabolism) and/or an increased volume of distribution (on a weight basis) of nifedipine in the pediatric population. Determination of the pharmacokinetic parameters of nifedipine after an i.v. dose in this patient population would be necessary to evaluate which of these possible explanations is responsible for this difference.

The Tmax values for nifedipine reported by Foster et al. (13), Feher et al. (8), and Palma-Aguirre et al. (14) after oral administration of a $10-\mathrm{mg}$ capsule were $0.57,0.53$, and $0.5 \mathrm{~h}$, respectively, as compared to $1.0 \mathrm{~h}$ observed in this study. The fact that the patients in the current study were lightly sedated and recumbent may have contributed to the delay in the observed Tmax, especially for patients 4,8 , and 9 (Table 2); however, profiles consistent with fast and slow absorption were also noted by Foster et al. (13). The AUC values reported by Feher et al. (8) and Palma-Aguirre et al. (14) were 633 and $772 \mathrm{nmol} \cdot \mathrm{h} / \mathrm{L}$, respectively, and were also similar to the value of $760 \mathrm{nmol} \cdot \mathrm{h} /$ $\mathrm{L}$ determined in this study. An AUC value of $361 \mathrm{nmol} \cdot \mathrm{h} / \mathrm{L}$ was reported by Foster et al. (13) and exemplifies the considerable variability in plasma nifedipine concentrations occurring among normal subjects. The mean elimination $t_{1 / 2}$ for nifedipine after administration of a single $10-\mathrm{mg}$ oral capsule has been reported to range from 2.4 to $3.4 \mathrm{~h}(13,15)$ in normal adult volunteers and was determined to be $1.8 \mathrm{~h}$ in this study.

The pulmonary artery hypertension in each child in the study was partially reversible, as evidenced by the acute decreases in mPAP and PR after nifedipine administration. The decrease in mPAP ranged from 12 to $51 \%$, and the decrease in PR from 10 to $58 \%$ of baseline measurements. Although significantly improved, the MPAP and PR values were not normalized after nifedipine administration in any child, suggesting that there may be an element of fixed pulmonary vascular disease present in these patients. Three children had a transient decrease in AOP of greater than $15 \%$ (range $25-40 \%$ ), which also correlated with the Cmax in these patients. No other adverse effects were noted in any child. The percentage change from baseline in the mPAP and PR were approximately double the percentage change in the AOP (Table 3), suggesting that nifedipine acted somewhat selectively on the pulmonary vascular bed. This selectivity was also demonstrated by the consistent decrease over time in the mean ratio of pulmonary vascular resistance to systemic vascular resistance.

A review of the published studies evaluating the relationship between pharmacokinetics and pharmacodynamics of nifedipine in adults by Kleinbloesem et al. (16) has concluded that the

Table 3. Hemodynamic responses to nifedipine in children with BPD and pulmonary hypertension

\begin{tabular}{|c|c|c|c|c|c|c|c|}
\hline \multirow[b]{2}{*}{ Time† } & \multirow[b]{2}{*}{ NIF $\ddagger$} & \multicolumn{6}{|c|}{ Hemodynamic parameter* } \\
\hline & & $\begin{array}{l}\text { mPAP } \\
(\mathrm{kPa}) \S\end{array}$ & $\mathrm{PR} \|$ & PR/SRT & $\mathrm{CI}^{* *}$ & $\begin{array}{c}\text { AOP } \\
(\mathrm{kPa}) \S\end{array}$ & AOS $+\dagger$ \\
\hline 0 & & $8.6 \pm 3.3$ & $14 \pm 7$ & $0.91 \pm 0.43$ & $4.2 \pm 1.4$ & $9.0 \pm 1.5$ & $80 \pm 8.3$ \\
\hline 0.083 & 118.8 & $7.0 \pm 3.0(-14)+4$ & $13 \pm 9(-14)$ & $0.91 \pm 0.51(-3)$ & $4.3 \pm 2.2(0.5)$ & $7.8 \pm 1.2(-9)$ & $80 \pm 9.6$ \\
\hline 0.50 & 229.2 & $6.6 \pm 2.7(-21) \neq \ddagger$ & $10 \pm 6(-27)+t$ & $0.81 \pm 0.37(-8)$ & $4.8 \pm 2.6(8)$ & $8.0 \pm 2.1(-13)$ 新 & $80 \pm 12.3$ \\
\hline 1.00 & 176.3 & $6.4 \pm 2.5(-24)+4$ & $11 \pm 7(-21)+末$ & $0.81 \pm 0.50(-13)$ & $4.2 \pm 1.8(-2)$ & $8.1 \pm 1.5(-11) \neq+$ & $80 \pm 11.3$ \\
\hline
\end{tabular}

* Values are mean \pm SD. Numbers in parentheses are the mean \% change in hemodynamic parameter compared with time 0 immediately before nifedipine administration.

$\dagger$ After nifedipine dose (h).

$\ddagger \mathrm{NIF}$, mean plasma nifedipine concentration $\mathrm{nmol} / \mathrm{L}(2.89 \mathrm{nmol} / \mathrm{L}=1 \mathrm{ng} / \mathrm{mL})$.

$\$ 1 \mathrm{~mm} \mathrm{Hg}=0.133 \mathrm{kPa}$.

II PR, pulmonary vascular resistance (indexed wood units).

I PR/SR, ratio of pulmonary vascular resistance/systemic vascular resistance.

** $\mathrm{Cl}$, cardiac index $\left(\mathrm{L} / \mathrm{min} / \mathrm{m}^{2}\right)$.

$+t$ AOS, arterial oxygen saturation (\%).

$\ddagger \ddagger p 0.05$ as compared with time zero measurement. 

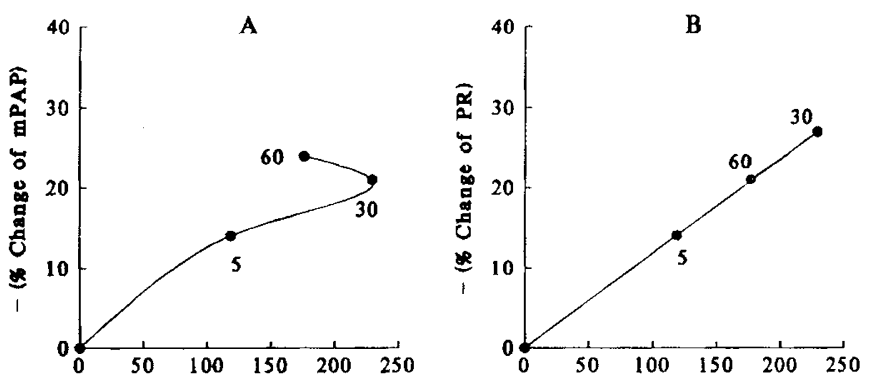

Nifedipine Concentration (nmol/L) Nifedipine Concentration (nmol/L)

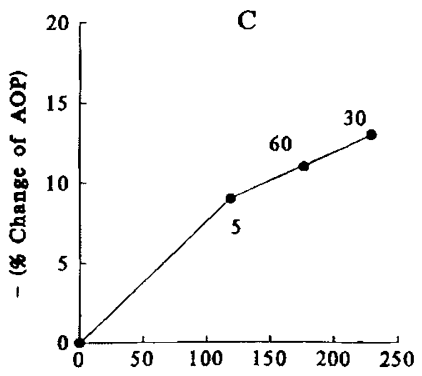

Nifedipine Concentration (nmol/L)

Fig. 2. Correlation of percentage change from baseline of mPAP (panel A), PR (panel B), and AOP (panel $C$ ) with mean plasma nifedipine concentration in order of time (min) after the dose.

equilibrium delay for nifedipine between plasma and the site of action is very small and that plasma nifedipine concentrations correlate closely with hemodynamic responses. Such studies have not been performed previously in the pediatric population. We examined this relationship using hysteresis plots (Fig. 2). In these plots, the equilibrium delay between plasma drug concentrations and the site of the drug's effect is represented by the area contained within the hysteresis loop. After extrapolation of the plots of mean hemodynamic response versus mean plasma nifedipine concentration to baseline, little or no area was observed within any of the hysteresis loops. This finding is in agreement with the proposed linear relationship between plasma nifedipine concentrations and concentrations at the site of action in vascular smooth muscle (16).

The use of nifedipine in children with BPD and pulmonary artery hypertension remains under investigation. The potential adverse effects of systemic arterial hypotension, tachycardia, increased intrapulmonary right to left shunting, and negative ionotropic effects must be considered in each child $(17,18)$. For these reasons and because the pulmonary vascular effects must be documented acutely, it is recommended that the acute effects of nifedipine be evaluated in each child in the cardiac catheterization laboratory before the potential use of the drug (4). The data from our study suggest that the intensity of the pulmonary vascular response closely correlates with the plasma nifedipine concentration. The effect was also greater on the pulmonary as compared with the systemic vascular bed. Based on the pharmacokinetic and pharmacodynamic properties of nifedipine determined in this study, an initial oral maintenance regimen of $1.44 \mu \mathrm{mol} / \mathrm{kg}(0.5 \mathrm{mg} / \mathrm{kg})$ every $6 \mathrm{~h}$ would be needed for this patient population. Individual patients, however, may require titration of the nifedipine dosage based on the initial response. Sustained reduction of pulmonary artery hypertension may contribute to the preservation of right ventricular function and reduce overall morbidity and mortality in children with BPD (19-21). Whether or not these responses will be maintained after chronic oral therapy with nifedipine remains to be determined, inasmuch as kinetic and dynamic parameters have been reported to change after continuous therapy, indicating the potential development of tolerance at the vascular level (22). If the safety and efficacy after chronic therapy can also be shown, nifedipine may prove to be an important therapeutic addition to the management of children with BPD and pulmonary hypertension.

Acknowledgment. The authors thank Catherine E. Brown, B.S.N. for her assistance in collection of the data.

\section{REFERENCES}

1. Northway W, Rosan R, Porter D 1967 Pulmonary disease following respiratory therapy of hyaline membrane disease. N Engl J Med 276:357-368

2. Stahlman M 1979 Clinical description of bronchopulmonary dysplasia. J Pediatr 95:829-834

3. Kochanek P, Zaritsky A 1986 Nifedipine in the treatment of a child with pulmonary hypertension associated with severe bronchopulmonary dysplasia. Clin Pediatr (Phila) 25:214-216

4. Brownlee JR, Beekman RH, Rosenthal A 1988 Acute hemodynamic effects of nifedipine in infants with bronchopulmonary dysplasia and pulmonary hypertension. Pediatr Res 24:186-190

5. Barst RJ 1986 Pharmacologically induced pulmonary vasodilation in children and young adults with primary pulmonary hypertension. Chest 89:497-503

6. Robertson DRC, Waller DG, Renwick AG, George CF 1988 Age-related changes in the pharmacokinetics and pharmacodynamics of nifedipine. $\mathrm{Br} \mathrm{J}$ Clin Pharmacol 25:297-305

7. Gutierrez LM, Lesko LJ, Whipps R, Carliner N, Fisher M 1986 Pharmacokinetics and pharmacodynamics of nifedipine in patients at steady state. $J$ Clin Pharmacol 26:587-592

8. Feher MD, Oates BJ, Schmid HE, Perry HE, Sever PS, Idle JR 1988 Metabolism and pharmacokinetics of two formulations of nifedipine. J Drug Dev 1(2):93-97

9. Walley TJ, Heagerty AM, Woods KL, Bing RF, Pohl JEF, Barnett DB 1987 Pharmacokinetics and pharmacodynamics of nifedipine infusion in normal volunteers. Br J Clin Pharmacol 23:693-701

10. Harrod JR, L'Heureux P, Wagensteen OD, Hunt CE 1974 Long term followup of severe respiratory distress syndrome treated with IPPB. J Pediatr $84: 277-286$

11. Rosen WJ, Johnson CE 1989 Evaluation of five procedures for measuring nonstandard doses of nifedipine liquid. Am J Hosp Pharm 46:2313-2317

12. Pietta P, Rava A, Biondi P 1981 High-performance liquid chromatography of nifedipine, its metabolites and photochemical degradation products. J Chromatogr 210:516-521

13. Foster TS, Hamannn SR, Richards VR, Bryant PJ, Graves DA, McAllister RG 1983 Nifedipine kinetics and bioavailability after single intravenous and oral doses in normal subjects. J Clin Pharmacol 23:161-170

14. Palma-Aguirre JA, Rosas-Alcazar G, Rodriguez JM, Leon-Urrea F, MontoyaCabrea MA 1989 Bioavailability and pharmacokinetics of nifedipine administered by different routes in healthy volunteers. Arch Invest Med 20:129135

15. Kleinbloesem $C H$, van Brummelen $P$, Faber $H$, Danhof $M$, Vermeulen NPE, Breimer DD 1984 Variability in nifedipine pharmacokinetics and dynamics: a new oxidation polymorphism in man. Biochem Pharmacol 33:3721-3724

16. Kleinbloesem CH, van Brummelen P, Breimer DD 1987 Nifedipine: relationship between pharmacokinetics and pharmacodynamics. Clin Pharmacokinet 12:12-29

17. Katz AM, Hager WD, Messino FC, Pappano AJ 1984 Cellular actions and pharmacology of the calcium channel blocking drugs. Am J Med 77:2-10

18. Simoneau G, Escourrou P, Duroux P, Lockhart A 1981 Inhibition of hypoxic pulmonary vasoconstriction by nifedipine. N Engl J Med 304:1582-1585

19. Fouron JC, LeGuenner JC, Villemant D, Bard H, Perrault G, Davignon A 1980 The outcome of bronchopulmonary dysplasia of the newborn. Pediatrics 65:529-535

20. Abman SH, Wolfe RR, Accurso PS, Koops BL, Bowman M, Wiggins $J_{r} J W$ 1985 Pulmonary vascular response to oxygen in infants with severe bronchopulmonary dysplasia. Pediatrics 75:80-84

21. Berman $J_{r}$ W, Yabek SM, Dillon T, Burstein R, Corlew S 1982 Evaluation of infants with bronchopulmonary dysplasia using cardiac catheterization. Pediatrics 70:708-711

22. Kleinbloesem CH, van Brummelen P, Faber H, Breimer DD 1987 Pharmacokinetics and haemodynamic effects of long term nifedipine treatment in hypertensive patients. J Cardiovasc Pharmacol 9:202-208 